\title{
A cohort study to evaluate infection prevention protocol in pediatric trauma patients with blunt splenic injury in a Dutch level I trauma center
}

This article was published in the following Dove Press journal: Patient Preference and Adherence

\author{
Roy Spijkerman \\ Michel PJ Teuben \\ Falco Hietbrink \\ William LM Kramer \\ Luke PH Leenen
}

Department of Surgery, University Medical Centre Utrecht, Utrecht, the Netherlands
Correspondence: Roy Spijkerman Department of Surgery, University Medical Center Utrecht, Heidelberglaan 100, 3584 CX Utrecht, the Netherlands $\mathrm{Tel}+3 \mid 88755$ I485

Fax +3I 887555015

Email spijkermanroy@gmail.com
Purpose: Asplenic patients are at increased risk for the development of overwhelming postsplenectomy infection (OPSI) syndrome. It is believed that adequate immunization, antimicrobial prophylaxis, as well as appropriate education concerning risks on severe infection lead to the decreased incidence of OPSI. The aim of this study was to analyze the methods used to prevent OPSI in trauma patients splenectomized before the age of 18.

Patients and methods: A retrospective, single-center study of all pediatric patients sustaining blunt splenic injury (BSI) managed at our level 1 trauma center from January 1979 to March 2012 was performed. A questionnaire was sent to all the included patients to determine the level of knowledge concerning infection risks, the use of antibiotics, and compliance to vaccination recommendations. Furthermore, we investigated whether the implementation of guidelines in 2003 and 2011 resulted in higher vaccination rates.

Results: We included 116 children with BSI. A total of 93 completed interviews were eligible for analysis, resulting in a total response rate of $80 \%$ and 1,116 patient years. Twenty-seven patients were splenectomized, and 66 patients were treated by a spleen preserving therapy (including embolization). Only two out of 27 splenectomized patients were adequately vaccinated, five patients without a spleen used prophylactic antibiotics, and about half of the asplenic patients had adequate knowledge of the risk that asplenia entails. A total of 22/27 splenectomized patients were neither adequately vaccinated nor received prophylactic antibiotics. There was no OPSI seen in our study population during the 1,116 follow-up years.

Conclusion: The vaccination status, the level of knowledge concerning prevention of an OPSI, and the use of prophylactic antibiotics are suboptimal in pediatric patients treated for BSI. Therefore, we created a new follow-up treatment guideline to have adequate preventive coverage to current standards for these patients.

Keywords: spleen, blunt trauma, questionnaire, immunization, antibiotics, education

\section{Plain language summary}

After a motor vehicle accident or any other trauma, sometimes the spleen may be bleeding and may need to be removed. Children of whom the spleen was removed are at increased risk of developing severe infections for the rest of their lives. It is believed that vaccination status, the early use of antibiotics, and appropriate education concerning risks on severe infections lead to the decreased occurrence of severe infections. We studied the use of these preventive methods among children who have had a blunt splenic injury. We sent questionnaires to all patients who were admitted to our trauma center between 1979 and 2012. Ninety-three out of 116 completed questionnaires were received. After analyzing these questionnaires, we found that only two out of 27 patients without a spleen are adequately vaccinated, five patients without a spleen use preventive antibiotics when needed, and about half of these patients have sufficient knowledge of 
the risk that living without a spleen entails. We concluded that these findings concern suboptimal care. To improve the severe infection prevention we created a new treatment protocol for the aftercare of children who have had a blunt spleen trauma.

\section{Introduction}

Blunt abdominal trauma is a common presentation in the emergency department and $\sim 10 \%-22 \%$ of such patients have intraabdominal injuries. ${ }^{1,2}$ The spleen is the most commonly injured intraabdominal organ, accounting for up to $45 \%$ of all visceral injuries. ${ }^{3}$ When a splenectomy is unavoidable, patients are at an increased risk of developing an overwhelming postsplenectomy infection (OPSI). The description of this syndrome in 1952 led to a management shift toward preservation of splenic function in patients suffering blunt splenic injury (BSI). ${ }^{4,5}$ The annual risk of developing an OPSI in asplenic adult patients is $0.18 \%-0.42 \%$ and the lifetime risk of these patients is $\sim 5 \% .{ }^{6,7}$ Patients splenectomized for the treatment of traumatic splenic injury have an 8.6-fold increased risk of developing severe infection, compared to the general population. ${ }^{8}$ The documented mortality rate of an OPSI is up to $80 \%{ }^{9,10}$ Significant infection risk reduction can be achieved by adequate immunization, antimicrobial prophylaxis, as well as appropriate education about the increased risk of severe infections. ${ }^{11,12}$ Despite the existence of guidelines with recommendations for education, vaccinations, and prophylactic antibiotics, the compliance to these recommendations differs among surgeons. ${ }^{13,14}$ Previous studies showed inadequate vaccination coverage and reported that up to $70 \%$ of these patients have insufficient awareness of infectious risks in adult asplenic patients. ${ }^{15,16}$ Therefore, the aim of this study was to analyze vaccination rate, the use of antibiotic prophylaxis, and the level of knowledge concerning prevention of an OPSI in trauma patients splenectomized before the age of 18 .

\section{Patients and methods}

We performed a retrospective, single-center, cohort study in which we included all patients up to and including 18 years of age who were admitted to our level 1 trauma center for the treatment of BSI between January 1, 1979, and March 14, 2012. A follow-up time period of at least 1 year was required; therefore, we started our study in May 2013. This questionnaire study was reviewed by the institutional review board (IRB) as a study with minimal risk for the patient and therefore an IRB waiver was obtained (protocol no. 10-382C). Patients were identified from the hospitals discharge register. Exclusion criteria are mortality during or after initial hospital admission. A questionnaire was sent to all included patients or caretakers to determine the vaccination status, the level of knowledge about infectious risks, and prophylactic antibiotic treatment. We tried to contact all patients who did not respond to the questionnaire by phone. Written informed consent was obtained from all individual participants included in the study. When patients were younger than 18 years at the time of the study, legal representatives were involved in the informed consent process. If patients were unable to provide written informed consent, verbal informed consent was obtained. Patients were excluded from the analysis if they neither responded to the questionnaire nor to multiple phone calls or if they refused to participate.

\section{Endpoints}

Our primary endpoints were 1) current vaccination status; 2) prophylactic use of antibiotics; and 3) level of knowledge regarding infectious risks. Our secondary endpoints were defined as 1) type of health care worker proving information; 2) providing written information; 3) knowledge of antibiotic use on demand; and 4) development of OPSI.

\section{Clinical data}

All patient charts and follow-up files were reviewed by two investigators (RS, MT) and patient characteristics, trauma characteristics, treatment, and outcome were documented. For each patient we collected the date of trauma, gender, age, mechanism of injury, Abbreviated Injury Score (AIS) of splenic injury, ${ }^{17}$ Injury Severity Score (ISS), ${ }^{18}$ final type of treatment for the BSI, duration of intensive care unit (ICU) stay, length of hospital stay, and mortality. We also gathered information regarding the inhospital development of OPSI.

\section{Development of vaccination guidelines}

In 2003, the national Health Council of the Netherlands developed new vaccination guidelines for asplenic patients. ${ }^{19}$ These guidelines pointed out the necessity of Pneumococcus vaccination in asplenic patients. The guidelines resulted in changes of our institutions' vaccination regime and we implemented these changes in the same year. To investigate the impact of the introduction of the new 2003 guidelines we performed a sub-analysis of the vaccination status in which we compared the time period before 2003 and the period after 2003. Parallel to this development, literature emphasized the importance of other vaccinations like haemophilus influenza type b (Hib), meningococcus, and influenza. ${ }^{14,20}$ In 2011 , the National Institute for Public Health and Environment developed a new protocol for hypo-splenic and asplenic 
patients. ${ }^{21}$ This protocol underlined the importance of adequate vaccination for the following bacteria: Streptococcus pneumoniae, Hib, and Neisseria meningitides. The yearly influenza vaccination was also additionally recommended in this protocol. Furthermore, the 2011 protocol advised to prescribe prophylactic antibiotics for at least 2 years and give lifelong antibiotics on demand in splenectomized patients.

\section{Questionnaire or interview}

We used the electronic hospital registry to acquire the patients' current contact information. Patients or their legal guardians were interviewed by the use of a short and standardized questionnaire. This questionnaire included a total of nine simplified questions aimed to explore the postsplenectomy infection risks, antibiotic prophylaxis, and compliance to vaccination recommendations. They were also asked which health care worker provided this information. The questionnaire was critically reviewed by a statistician experienced in these survey techniques and an independent clinician experienced in this field. The first question, about the inhospital treatment, was used to verify reliability on the recall of information. Furthermore, we checked all vaccinations and antibiotics registered in our hospital patient registry to verify patient reliability. The specific questions that patients were asked are shown in Figure S1. Participants were first contacted by surface mail and invited to fill out the questionnaire. In the absence of a response to this letter, they were contacted by phone. In case children were under the age of 16 at the time of the interview, a parent participated in the telephone interview. Written consent for the use of data was obtained from all the participating patients or their parents.

\section{Data analysis}

Patients were grouped based on the treatment they received. Group A consists of patients treated by total splenectomy. Patients who underwent spleen preserving therapy such as nonoperative management (NOM), selective angioembolization, and operation with hemostatic mesh technique were assigned to group B. The final treatment was verified by checking the patients' charts and by a specific question added to the interview. Both investigators (RS, MT) who analyzed the outcomes were blinded to group assignment. In order to describe the development of treatment management and function tests we divided patients into five groups. Group 1 consisted of patients treated before 1980, group 2 included all patients admitted between 1981 and 1990, group 3 included individuals admitted between 1991 and 2004, group 4 those who were admitted between 2005 and 2009, and group 5 consisted of patients treated from 2010 and later. Age at follow-up and follow-up time were set at the date the patient completed the questionnaire. Patient years were calculated from the date of admission in the hospital for the treatment of BSI until the date the patient completed the questionnaire. Statistical analysis was performed using SPSS for Windows 20.0 (IBM Corporation, Armonk, NY, USA). Differences between groups were calculated with Fisher's exact test and chi-squared test for ordinal data and Mann-Whitney $U$ test for continuous data. $P$-values $<0.05$ were considered significant.

\section{Approval and consent}

All procedures performed in this study involving human participants were in accordance with the ethical standards of the institutional ethical research committee and with the 1964 Declaration of Helsinki and its later amendments. Informed consent was obtained from all individual participants included in the study.

\section{Results}

A total of 93 completed interviews were eligible for analysis, resulting in a total response rate of $80 \%$. Recruitment and dropout of study participants are shown in Figure 1. Three excluded patients died as a result of their neurological injuries. Sixty-six individuals were men and the median (interquartile range [IQR]) AIS of the splenic injury was 3 (3-4). The population had a median (IQR) ISS of 16 (9-27) and for the treatment of their traumatic injuries they were hospitalized for 11 (8-19) days. The median (IQR) ICU stay was 2 (1-5) days. Sixty-one splenic injuries were due to trafficrelated accidents, 21 children fell from a height, a fallen object hit two, four sport-/assault-related injuries occurred, and five mechanisms of injuries were not documented. The median (IQR) age at the date of trauma of the participants was $14(9-17)$ years and they were $22(16-31)$ years of age at the time of the interview. The median (IQR) duration of follow-up was 8 (4-18) years and the study represents 1,116 cumulative patient years. The majority of the patients (62\%) were included between 2003 and 2012. Baseline and follow-up characteristics are summarized in Table 1.

Splenic injury was treated by NOM in 57 patients, 27 patients were splenectomized, angio-embolization was performed in two patients, and a hemostatic mesh technique was used in seven patients. During the inclusion period, we see a shift toward conservative management of the splenic injury. Figure 2 summarizes the treatment modalities that were used during the different time intervals in our study period. 


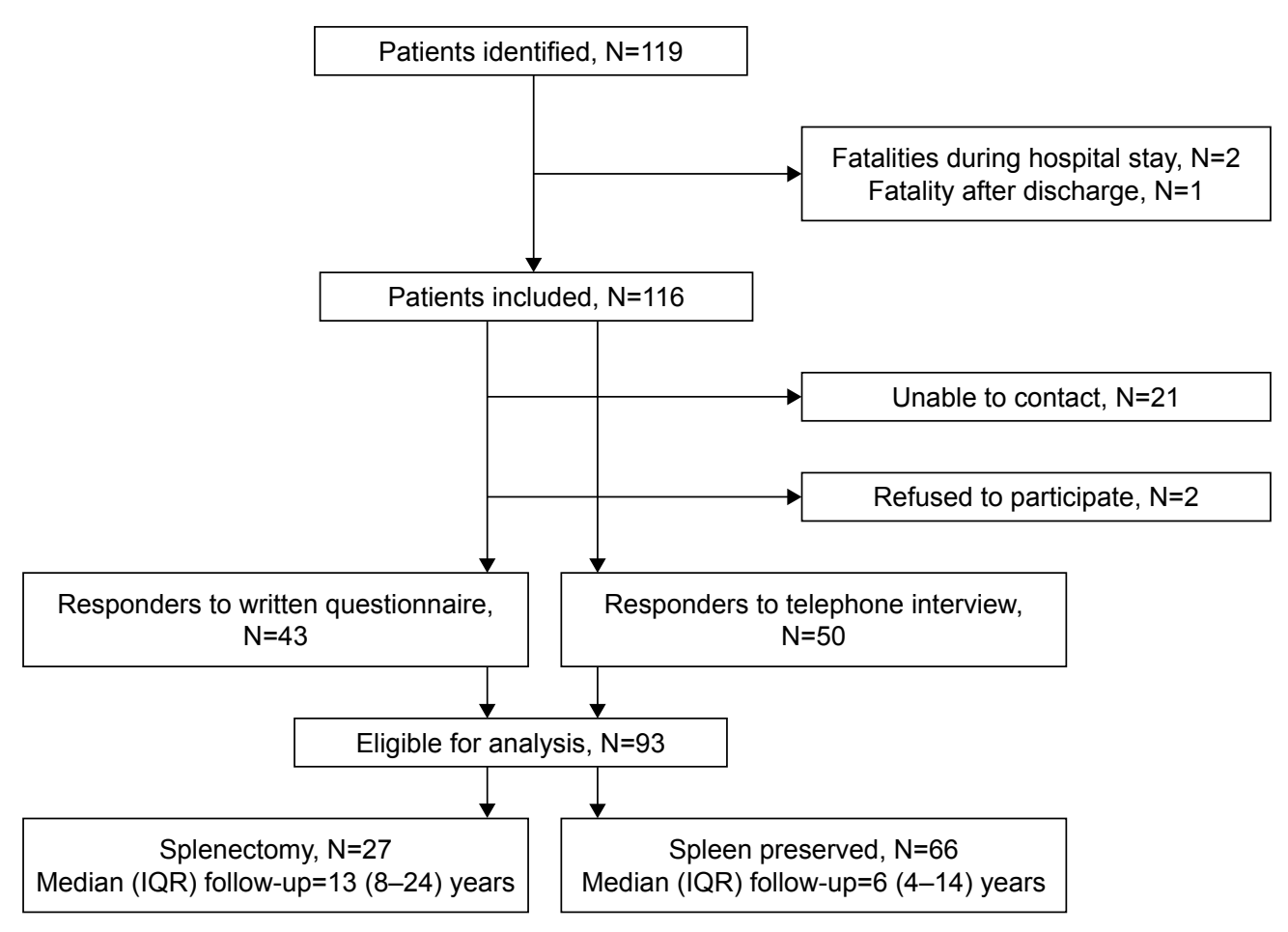

Figure I Flowchart of patients excluded from the study.

Abbreviation: IQR, interquartile range.

Patients treated by total splenectomy (group A) were significantly older when they were treated for their splenic injuries and when they participated in our study. This led to significantly more patient years per patient than patients treated by spleen preserving therapy (group B). However, because of a higher number of participants in group B, the cumulative number of patient years was higher in this group. A comparison of baseline and follow-up characteristics between group A (splenectomy) and group B (spleen preserving) is provided in Table 2.

Pneumococcus vaccination was given to eight out of 18 patients before 2003 and the number was significantly more frequent, eight out of nine, after 2003. Vaccination

Table I Baseline and follow-up characteristics

\begin{tabular}{ll}
\hline Characteristics & $\mathbf{N}=\mathbf{9 3}$ \\
\hline Gender (male/female) & $66 / 27$ \\
Splenic AIS & $3(3-4)$ \\
ISS & $16(9-27)$ \\
Intensive care unit stay (days) & $2(1-5)$ \\
Length of hospital stay (days) & $1 \mathrm{I}(9-19)$ \\
Age at trauma (years) & $14(9-17)$ \\
Age at follow-up (years) & $22(16-31)$ \\
Patient years per patient (years) & $8(4-18)$ \\
Total patient years of all responders & $\mathrm{I}, \mathrm{II6}$ \\
\hline
\end{tabular}

Note: All variables are shown in number or median $(25 \%-75 \%)$.

Abbreviations: AIS, Abbreviated Injury Score; ISS, Injury Severity Score. against Hib was given in three out of 18 individuals before 2003 and significantly more, in six out of nine patients, after the introduction of new guidelines. The same was true for meningococcal vaccination, which was provided significantly less to participants (5/16) admitted before 2003 than to those treated after 2003 (seven out of nine). The yearly influenza vaccination was provided to three out of 16 patients treated before 2003 and four out of seven patients treated

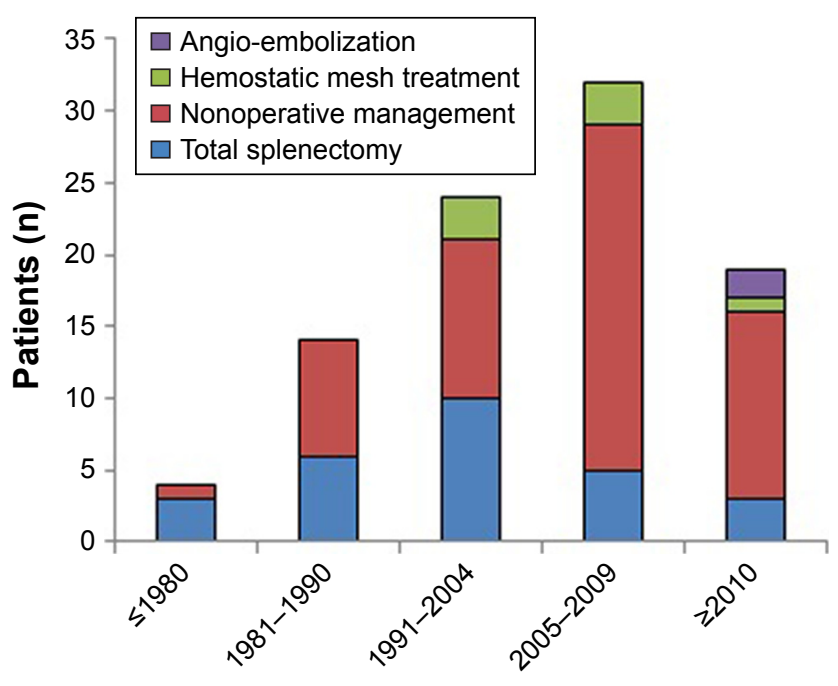

Figure 2 Treatment modalities of blunt splenic injury in time. 
Table 2 Comparison of baseline and follow-up characteristics between patients treated by total splenectomy and patients treated by spleen preserving therapy

\begin{tabular}{llll}
\hline Characteristics & Total splenectomy N=27 & Spleen preserving therapy N=66 & P-value \\
\hline Gender (male/female) & $19 / 8$ & $48 / 18$ & NS \\
Splenic AIS & $4(4-5)$ & $3(3-4)$ & $<0.05$ \\
Number of patients with AIS score spleen $\leq 3$ & $13(48 \%)$ & $44(67 \%)$ & NS \\
Number of patients with AIS score spleen 4 & $11(41 \%)$ & $20(30 \%)$ & NS \\
Number of patients with AIS score spleen 5 & $3(11 \%)$ & $2(3 \%)$ & NS \\
ISS & $25(16-34)$ & $16(9-21)$ & $<0.05$ \\
Intensive care unit stay (days) & $5(0-14)$ & $2(1-3)$ & NS \\
Length of hospital stay (days) & $19(8-30)$ & $10(8-15)$ & $<0.05$ \\
Age at trauma (years) & $17(16-18)$ & $12(7-16)$ & $<0.05$ \\
Age at follow-up (years) & $28(23-43)$ & $20(14-26)$ & $<0.05$ \\
Patient years per patient & $13(8-24)$ & $6(4-14)$ & $<0.05$ \\
Total patient years of all responders & 438 & 678 & $<0.05$ \\
\hline
\end{tabular}

Note: All variables are shown in number (\%) or median (25\%-75\%).

Abbreviations: AIS, Abbreviated Injury Score; ISS, Injury Severity Score; NS, not significant.

after 2003. Two patients did not answer the question about influenza vaccination. Only two patients received the full vaccination program as recommended by the most recent guidelines. The results concerning the vaccination status are given in Figure 3. Ten patients were vaccinated in the hospital and seven patients were vaccinated by the general practitioner.

Table 3 shows the answer on questions concerning antibiotic use and level of knowledge. Five asplenic patients were advised to use prophylactic antibiotics for a duration of 2 years and 11 patients were advised to have antibiotics on demand. Two of these patients were injured after the introduction of the 2011 infection prevention guidelines; the rest were injured before the introduction of the guidelines.

Analysis of the level of knowledge about potential risks of asplenia of the splenectomized patients showed that 20 out of 27 patients were aware of the increased risk of severe infection. Eleven patients knew how to act in the case of fever and eight patients were aware of the risks associated with a dog or a cat bite. Furthermore, 10 out of 27 patients indicated that they received a handout information document with information about their infection risk. In the total patient

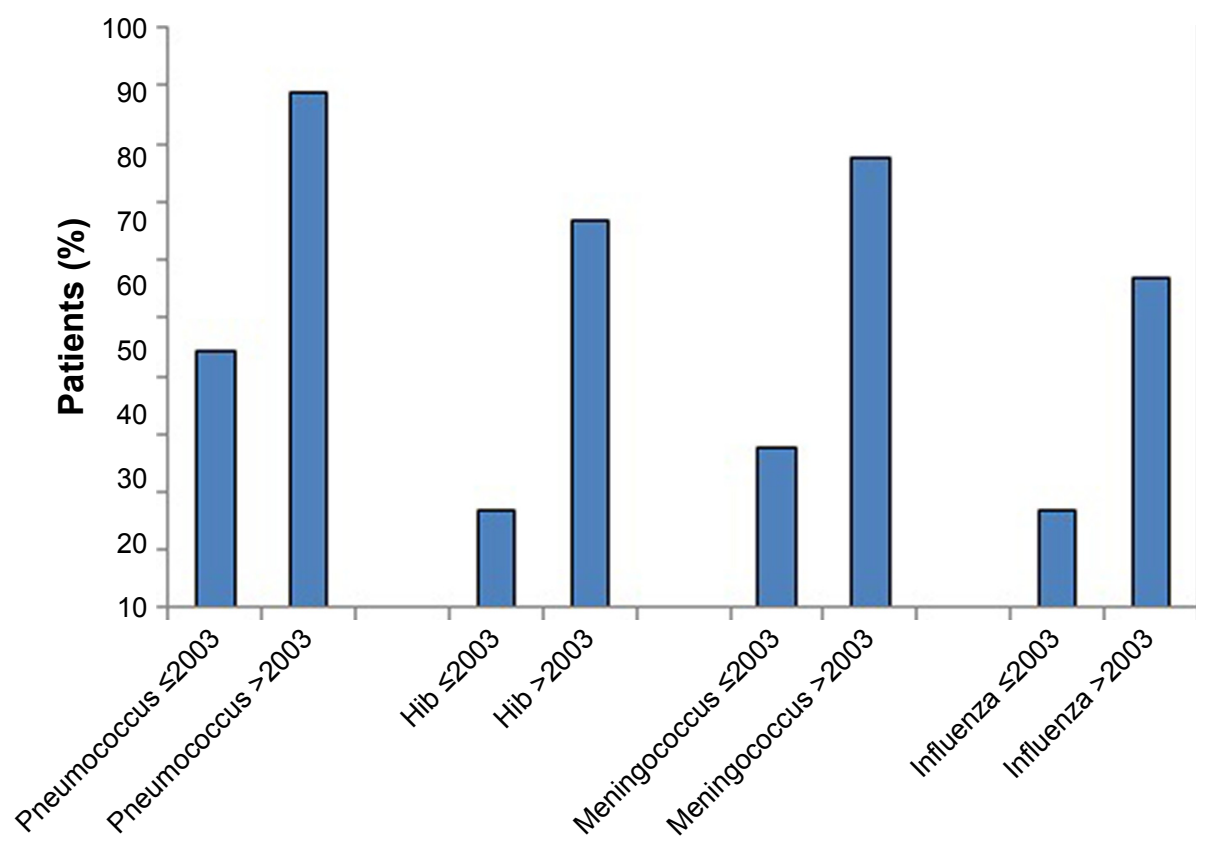

Figure 3 Percentage of asplenic trauma patients that received the vaccination before and after the introduction in 2003 of a new institutional vaccination protocol. Abbreviation: Hib, haemophilus influenza type b. 
Table 3 Outcome of questionnaire analysis: use of antibiotics and level of knowledge regarding infectious risks in splenectomized pediatric trauma patients

\begin{tabular}{ll}
\hline Patient response to questionnaire & Total \\
& splenectomy \\
& $\mathbf{N}=27$ \\
\hline
\end{tabular}

Level of knowledge

Aware of the increased risk of severe infection 20

Adequate knowledge about how to react in case II

of fever

Adequate knowledge about the potential risk of a 8

cat/dog bite

Received a handout information document $\quad 10$

Use of antibiotics

Prophylactic antibiotic use during 2 years 5

Antibiotics on demand II

Note: All variables are shown in number.

group, there was no OPSI seen during hospital admission or during the follow-up period.

\section{Discussion}

A combination of three factors can reduce the prevalence of the OPSI syndrome in asplenic patients; these are adequate immunization, the use of prophylactic antibiotics, and proper education concerning infection risks. These recommendations are widely described throughout the literature. ${ }^{12,22}$ This study shows that there is a huge lack of compliance to all kinds of recommendations concerning these three factors in pediatric patients splenectomized for the treatment of BSI. Only two out of 27 splenectomized patients were adequately vaccinated, five patients without a spleen used prophylactic antibiotics, and only about half of the asplenic patients had adequate knowledge of the risk that asplenia entails. Although highly recommended in current literature, the low compliance in this current study did not result in any OPSI episodes.

\section{Immunization}

Strict adherence to immunizations for splenectomized patients is recommended by several guidelines. Hence, previous studies showed poor adherence to these recommendations in several institutions. A study by Ejstrud et al demonstrated that only $37.5 \%$ of trauma patients were immunized in accordance with published guidelines. ${ }^{23}$ Lammers et al investigated the management of postsplenectomy patients in a representative sample of Dutch hospitals from 1997 up to $2008 .^{22}$ They included academic, teaching, and nonteaching institutions and found the highest reported pneumococcus vaccination rates in the literature. However, their overall pneumococcal vaccination rate of $85.5 \%$ leaves still $14.6 \%$ of asplenic patients unvaccinated against S. pneumoniae. Additionally, immunization against meningococcus was not given in $60.6 \%$, while $67.7 \%$ of patients did not receive Hib vaccinations. Further analysis of subgroups delineates that the pneumococcal vaccination rates are lower in patients that underwent a splenectomy in the acute setting or if the decision to perform splenectomy was made during surgery. This finding suggests that patients who undergo splenectomy in a nonelective setting are prone for suboptimal aftercare. Therefore, we expected to have a lower compliance rate of immunization in our study. In our study, a total of 16 out of 27 splenectomized patients were vaccinated for S. pneumoniae. The vaccination rate increased from $8 / 18$ before 2003 to $8 / 9$ after 2003. The improvement of vaccination rates after the implementation of the new guidelines puts our results on par with the results from Lammers et al. ${ }^{22}$

\section{Prophylactic antibiotics}

A study by Jugenburg et al revealed that the use of prophylactic antibiotics results in a reduction of sepsis-related mortality in asplenic pediatric patients from $88 \%$ to $47 \%{ }^{24}$ Asplenia results in a lifelong increased risk of severe infection and therefore some investigators say that prophylactic antibiotics are indicated for the rest of the asplenic patients life. ${ }^{25}$ However, half of the cases of severe sepsis are seen in the first 2 years and 30\% within the first year after splenectomy. ${ }^{26}$ So, due to the potential development of antibiotic resistant strains, antibiotics-related side effects, and therapy compliance, most guidelines recommend prescribing antibiotics only for the first 24 months following splenectomy. ${ }^{11,27}$ However, the guidelines used throughout the world are far from similar. The Dutch guidelines for children from 2011 advise the use of prophylactic antibiotics for at least 2 years after splenectomy mandatorily. ${ }^{21}$ Despite these guidelines, we only found that five patients were advised to use prophylactic antibiotics during the first 2 years after splenectomy.

\section{Education}

Meerveld-Eggink et al performed a questionnaire study on all adult asplenic patients in one region during the period 2006-2007 in the Netherlands to study knowledge of infection risks. ${ }^{15}$ They showed that 56 out of 130 (43\%) included patients were not aware of the increased risk of infections and the need for preventive measurement. Information was provided by their general practitioner in $43 \%$, travel clinics in $19 \%$, internists or surgeons in the hospital in only $15 \%$, 
and 30\% received information from other sources like the Internet. None of these patients received written information. These findings suggest that proper education is far from optimal in adult asplenic patients. Furthermore, this shows that the hospital, the location that should provide this information, is not performing well on this subject. Our study in pediatric trauma patients treated in a level 1 trauma center shows slightly better outcomes, although there is still need for improvement. Twenty out of 27 (74\%) asplenic patients have adequate awareness of the increased risks of severe infection associated with asplenia and a total of 10 patients $(37 \%)$ received written information.

\section{Limitations and strengths}

A major potential limitation of this study is that the individuals interviewed were subject to recall bias. The patients in this study were unlikely to recall the immunizations received after the splenectomy which, for many, was $>20$ years prior to the study interview. Especially, in this specific group, patients were likely to forget things due to associated neurotrauma or psychological stress associated with their trauma.
To minimize recall bias, we checked the vaccination and antibiotics given during hospital admission or during follow-up in the outpatient clinic. Furthermore, we added a question in the questionnaire to check if patient recalled their inhospital treatment.

The strong points of this study are the response rate of $80 \%$ and a total of 1,116 cumulative patient years. Ninetyone patients who were asked to participate in the survey responded to the questionnaire or were reachable by phone. Therefore, the study is not considered as one that is subjected to response bias and is probably a representative cohort of the entire population of pediatric splenic trauma patients in our institution. Besides that, we had the unique opportunity to measure the influence of the change in the treatment protocol regarding infection prevention.

\section{Treatment guidelines}

Altogether, our study shows that from 1979 up to 2012 infection prevention in our pediatric level 1 trauma center was suboptimal and needs improvement. Therefore, we created a treatment guideline in which we defined three groups, as can

Table 4 Follow-up treatment protocol for BSI in pediatric patients

\begin{tabular}{|c|c|c|}
\hline $\begin{array}{l}\text { Follow-up group I: } \\
\text { - NOM for grade I-3 splenic } \\
\text { injury }\end{array}$ & $\begin{array}{l}\text { Follow-up group 2: } \\
\text { - NOM for grade 4, } 5 \text { splenic injury } \\
\text { - angio-embolization } \\
\text { - spleen preserving surgery }\end{array}$ & $\begin{array}{l}\text { Follow-up group 3: } \\
\text { - total splenectomy }\end{array}$ \\
\hline $\begin{array}{l}\text { No indication for vaccinations, } \\
\text { education, or antibiotics }\end{array}$ & $\begin{array}{l}\text { Indication for: } \\
\text { - all vaccinations } \\
\text { - education } \\
\text { - prophylactic antibiotics for } 2 \text { years }\end{array}$ & $\begin{array}{l}\text { Indication for: } \\
\text { - all vaccinations } \\
\text { - education } \\
\text { - prophylactic antibiotics for } 2 \text { years }\end{array}$ \\
\hline $\begin{array}{l}\text { No consultation of pediatric } \\
\text { immunologist }\end{array}$ & $\begin{array}{l}\text { Consultation of pediatric immunologist } \\
\text { (task of trauma surgeon) }\end{array}$ & $\begin{array}{l}\text { Consultation of pediatric immunologist } \\
\text { (task of trauma surgeon) }\end{array}$ \\
\hline No education & $\begin{array}{l}\text { Education } \\
\text { (task of pediatric immunologist) }\end{array}$ & $\begin{array}{l}\text { Education } \\
\text { (task of pediatric immunologist) }\end{array}$ \\
\hline No antibiotics & $\begin{array}{l}\text { Patient starts directly with prophylactic } \\
\text { antibiotics for } 2 \text { years } \\
\text { (task of trauma surgeon) }\end{array}$ & $\begin{array}{l}\text { Patient starts directly with prophylactic } \\
\text { antibiotics for } 2 \text { years } \\
\text { (task of trauma surgeon) }\end{array}$ \\
\hline No vaccinations & $\begin{array}{l}\text { All needed vaccinations are provided } \\
2 \text { weeks after admission } \\
\text { (task of pediatric immunologist) }\end{array}$ & $\begin{array}{l}\text { All needed vaccinations are provided } 2 \text { weeks } \\
\text { after admission } \\
\text { (task of pediatric immunologist) }\end{array}$ \\
\hline $\begin{array}{l}\text { Letter to general practitioner with } \\
\text { policy concerning no indication for: } \\
\text { - vaccinations } \\
\text { - education } \\
\text { - prophylactic antibiotics } \\
\text { (task of trauma surgeon) }\end{array}$ & $\begin{array}{l}\text { Letter to general practitioner with policy } \\
\text { regarding: } \\
\text { - vaccinations } \\
\text { - education } \\
\text { - prophylactic antibiotics } \\
\text { - spleen function test } \\
\text { (task of pediatric immunologist) }\end{array}$ & $\begin{array}{l}\text { Letter to general practitioner with policy } \\
\text { regarding: } \\
\text { - vaccinations } \\
\text { - education } \\
\text { - prophylactic antibiotics } \\
\text { - revaccination } \\
\text { (task of pediatric immunologist) }\end{array}$ \\
\hline No follow-up imaging & $\begin{array}{l}\text { Order }{ }^{99 \mathrm{~m} T c-l a b e l e d,} \text {, heat-altered, } \\
\text { autologous erythrocyte spleen scintigraphy } \\
3 \text { months after discharge } \\
\text { (task of trauma surgeon) }\end{array}$ & No follow-up imaging \\
\hline
\end{tabular}


Table 4 (Continued)

\begin{tabular}{|c|c|c|}
\hline $\begin{array}{l}\text { Follow-up group I: } \\
\text { - NOM for grade I-3 splenic } \\
\text { injury }\end{array}$ & $\begin{array}{l}\text { Follow-up group 2: } \\
\text { - NOM for grade } 4,5 \text { splenic injury } \\
\text { - angio-embolization } \\
\text { - spleen preserving surgery }\end{array}$ & $\begin{array}{l}\text { Follow-up group 3: } \\
\text { - total splenectomy }\end{array}$ \\
\hline $\begin{array}{l}\text { No outpatient appointment indicated } \\
\text { for the prevention of infectious } \\
\text { complications }\end{array}$ & $\begin{array}{l}\text { Outpatient appointment to evaluate spleen } \\
\text { function test ( }>3 \text { months after discharge) } \\
\rightarrow \text { Adequate perfusion: } \\
\text { - stop use of antibiotics } \\
\text { - no indication for revaccination } \\
\text { - discharge patient from follow-up } \\
\text { (task of pediatric immunologist) } \\
\rightarrow \text { No adequate perfusion: } \\
\text { - continue use of antibiotics for } 2 \text { years } \\
\text { - indication for revaccination after } \\
5 \text { years } \\
\text { - make outpatient appointment to } \\
\text { evaluate infection prevention ( } 2 \text { and } \\
5 \text { years after discharge) } \\
\text { (task of pediatric immunologist) }\end{array}$ & $\begin{array}{l}\text { Outpatient appointment to evaluate infection } \\
\text { prevention ( } 2 \text { and } 5 \text { years after discharge) } \\
\text { - continue use of antibiotics for } 2 \text { years } \\
\text { - indication for revaccination after } 5 \text { years } \\
\text { When revaccinating, consider testing antibody } \\
\text { titers } \\
\text { (task of pediatric immunologist) }\end{array}$ \\
\hline
\end{tabular}

Abbreviations: BSI, blunt splenic injury; NOM, nonoperative management.

be seen in Table 4. Follow-up group 1 consisted of patients with grade 1-3 splenic injuries that were successfully treated by NOM. Patients who needed surgical interventions for other traumatic injuries, even when the spleen was left untouched, were also included in follow-up group 1. Follow-up group 2 included patients with possible impaired splenic functions, namely high-grade splenic injuries, patients undergoing angio-embolization, or patients where spleen preserving surgical techniques were used. Patients with total splenectomy were categorized into group 3.

The suggested treatment protocol included advice on immunization, prophylactic antibiotics, and proper education. After splenectomy is performed by a trauma surgeon, we believe that it is mandatory to send a patient to a (pediatric) immunologist for the follow-up protocol of the asplenic or hypo-splenic patient. Due to different guidelines in the world, our protocol does not include detailed information about immunization. Detailed local protocols need to be followed. The most important fact is that patients need to have an adequate titer at all times. Therefore, it is necessary to consider antibody titers before the follow-up meeting.

\section{Conclusion}

The vaccination status, level of knowledge concerning prevention of infections, and use of prophylactic antibiotics are suboptimal in pediatric patients treated for BSI. The aftercare for pediatric trauma patients who sustained BSI in our level 1 trauma center was not in compliance with best practice standards. This study shows that there is insufficient attention for possible infectious risks in asplenic pediatric patients.
Although no OPSI was seen in the current cohort, mortality remains high when it occurs. Therefore, we developed a new follow-up treatment guideline to adequately treat and follow pediatric patients with BSI. All asplenic pediatric patients need immunization, antibiotic prophylaxis, and education. Given the possible risk of OPSI, we advise all patients with a possible impaired splenic function to start with infection prevention as well. Furthermore, we advise sending asplenic and possible hypo-splenic patients to the pediatric immunology department for further follow-up regarding asplenia.

\section{Acknowledgment}

The authors are pleased to acknowledge Dr TJ Blokhuis for his work on this article.

\section{Disclosure}

The authors report no conflicts of interest in this work.

\section{References}

1. Richards JR, Knopf NA, Wang L, Mcgahan JP. Blunt abdominal trauma in children: evaluation with emergency US. Radiology. 2002;222(3): 749-754.

2. Capraro AJ, Mooney D, Waltzman ML. The use of routine laboratory studies as screening tools in pediatric abdominal trauma. Pediatr Emerg Care. 2006;22(7):480-484.

3. Tataria M, Nance ML, Holmes JH, et al. Pediatric blunt abdominal injury: age is irrelevant and delayed operation is not detrimental. $J$ Trauma. 2007;63(3):608-614.

4. King H, Shumacker HB. Splenic studies. I. Susceptibility to infection after splenectomy performed in infancy. Ann Surg. 1952;136(2):239-242.

5. Richardson JD. Changes in the management of injuries to the liver and spleen. J Am Coll Surg. 2005;200(5):648-669.

6. Lynch AM, Kapila R. Overwhelming postsplenectomy infection. Infect Dis Clin North Am. 1996;10(4):693-707. 
7. Schwartz PE, Sterioff S, Mucha P, Melton LJ, Offord KP. Postsplenectomy sepsis and mortality in adults. JAMA. 1982;248(18): 2279-2283.

8. Cullingford GL, Watkins DN, Watts AD, Mallon DF. Severe late postsplenectomy infection. Br J Surg. 1991;78(6):716-721.

9. Davidson RN, Wall RA. Prevention and management of infections in patients without a spleen. Clin Microbiol Infect. 2001;7(12):657-660.

10. di Sabatino A, Carsetti R, Corazza GR. Post-splenectomy and hyposplenic states. Lancet. 2011;378(9785):86-97.

11. Rubin LG, Schaffner W, Schaffner W. Clinical practice. Care of the asplenic patient. $N$ Engl J Med. 2014;371(4):349-356.

12. Kuchar E, Miśkiewicz K, Karlikowska M. A review of guidance on immunization in persons with defective or deficient splenic function. Br J Haematol. 2015;171(5):683-694.

13. Waghorn DJ. Overwhelming infection in asplenic patients: current best practice preventive measures are not being followed. J Clin Pathol. 2001;54(3):214-218.

14. Langley JM, Dodds L, Fell D, Langley GR. Pneumococcal and influenza immunization in asplenic persons: a retrospective population-based cohort study 1990-2002. BMC Infect Dis. 2010;10(1):219.

15. Meerveld-Eggink A, de Weerdt O, Rijkers GT, van Velzen-Blad H, Biesma DH. Vaccination coverage and awareness of infectious risks in patients with an absent or dysfunctional spleen in the Netherlands. Vaccine. 2008;26(52):6975-6979.

16. Grace RF, Mednick RE, Neufeld EJ. Compliance with immunizations in splenectomized individuals with hereditary spherocytosis. Pediatr Blood Cancer. 2009;52(7):865-867.

17. Moore EE, Cogbill TH, Jurkovich GJ, Shackford SR, Malangoni MA, Champion HR. Organ injury scaling: spleen and liver (1994 revision). J Trauma. 1995;38(3):323-324.

18. Baker SP, O'Neill B, Haddon W, Long WB. The severity score: a method for describing patients with multiple injuries and evaluating emergency care. J Trauma. 1974;14(3):187-196.
19. Health Council of the Netherlands. Pneumococcal Vaccine in Elderly Adults and Risk Groups. Publication no 2003/10. The Hague: Health Council of the Netherlands; 2003.

20. Ambrosino DM, Lee MY, Chen D, Shamberger RC. Response to Haemophilus influenzae type B conjugate vaccine in children undergoing splenectomy. J Pediatr Surg. 1992;27(8):1045-1048.

21. Lammers AJ, van der Maas N, Peters EJ, Meerveld-Eggink A, Sanders EA, Kroon FP; De Werkgroep voor Infectiepreventie bij Hyposplenia en Asplenia. Voorkomen van ernstige infecties bij patienten met hypo- of asplenie [Prevention of severe infections in patients with hyposplenism or asplenia]. Ned Tijdschr Geneeskd. 2012;156(44): A4857. Dutch.

22. Lammers AJ, Veninga D, Lombarts MJ, Hoekstra JB, Speelman P. Management of post-splenectomy patients in the Netherlands. Eur $J$ Clin Microbiol Infect Dis. 2010;29(4):399-405.

23. Ejstrud P, Hansen JB, Andreasen DA. Prophylaxis against pneumococcal infection after splenectomy: a challenge for hospitals and primary care. Eur J Surg. 1997;163(10):733-738.

24. Jugenburg M, Haddock G, Freedman MH, Ford-Jones L, Ein SH. The morbidity and mortality of pediatric splenectomy: does prophylaxis make a difference? J Pediatr Surg. 1999;34(7):1064-1067.

25. Holdsworth RJ, Irving AD, Cuschieri A. Postsplenectomy sepsis and its mortality rate: actual versus perceived risks. Br J Surg. 1991;78(9): 1031-1038.

26. Sumaraju V, Smith LG, Smith SM. Infectious complications in asplenic hosts. Infect Dis Clin North Am. 2001;15(2):551-565.

27. American Academy of Pediatrics, Committee on Infectious Diseases. In: Kimberlin DW, Brady MT, Jackson MA, Long SS, editors. Red Book: Report of the Committee on Infectious Diseases. Elk Grove Village: American Academy of Pediatrics; 2015. 


\section{Supplementary material}

Name:

Date of birth:

Date of questionnaire completion:

Did you underwent surgery where the spleen was removed?

$\square$ Yes

$\square$ No

1. Are you aware of a greater risk of infectious diseases (due to spleen removal)?

$\square$ Yes

$\square$ No

2. Are you aware of the fact that you should immediately contact the general practitioner in case of fever?

$\square$ Yes

$\square$ No

3. Are you aware of the fact that you should immediately contact the general practitioner in case you are bitten by a cat or a dog?

$\square$ Yes

$\square$ No

4. Have you been advised to use antibiotics the first two years after spleen injury to prevent infections?

$\square$ Yes, by the general practitioner

$\square$ Yes, by the medical specialist

$\square$ No

5. Do you have antibiotics at home, so it can be used in case you develop fever?

$\square$ Yes

$\square$ No

6. Did you receive written information about the risk of infections after splenic injury?

$\square$ Yes

$\square$ No

7. Have you had vaccinations in relation to the splenic injury during or after your hospital admission?

$\square$ No (Skip question 8 and start with question 9)

$\square$ Yes:

$\square$ Haemophilus influenzae type B (Hib) (Respiratory infection)

$\square$ Pneumococcal (Respiratory infection)

$\square$ Meningococcal (Meninges infection)

$\square$ Influenza, yearly (Viral infection)

$\square$ Other: (Please fill in)

$\square$ I don't know which vaccinations

8. If you are vaccinated, who performed the vaccination?

$\square$ General practitioner

$\square$ The public health doctor

$\square$ Medical specialist in the hospital

$\square$ Other: ................................ (Please fill in)

9. When was the last time you had a Pneumococcal vaccination?

$\square$ Less than 5 years ago

$\square$ Never or more than 5 years ago

$\square$ I don't know anymore

It is important that you completely fill in the following text box:

\begin{tabular}{|ll|}
\hline Date & $: . . . . . . .$. \\
City & $: \ldots$ \\
Signature & $:$ \\
\hline
\end{tabular}

Figure SI Questionnaire sent to all included patients. 
Patient Preference and Adherence

Dovepress

\section{Publish your work in this journal}

Patient Preference and Adherence is an international, peer-reviewed, open access journal that focuses on the growing importance of patient preference and adherence throughout the therapeutic continuum. Patient satisfaction, acceptability, quality of life, compliance, persistence and their role in developing new therapeutic modalities and compounds to optimize

Submit your manuscript here: http://www.dovepress.com/patient-preference-and-adherence-journ clinical outcomes for existing disease states are major areas of interest for the journal. This journal has been accepted for indexing on PubMed Central The manuscript management system is completely online and includes a very quick and fair peer-review system, which is all easy to use. Visit http://www. dovepress.com/testimonials.php to read real quotes from published authors. 